\title{
Humanismo y transhumanismo en el final de la metafísica: la era digital como paradigma de la metafísica de la subjetividad $^{1}$
}

\author{
Humanism, Transhumanism and the End of \\ Metaphysics: The Digital Age as the paradigm of the \\ Metaphysics of Subjectivity
}

Dune Valle Jimenez ${ }^{2}$

Universidad Sergio Arboleda, Colombia

Recepción: 18 de junio del 2020

Evaluación: 04 de julio del 2020

Aceptación: 20 de julio de 2020

1 Investigación realizada en el grupo de investigación CODICE de la Universidad Sergio Arboleda.

2 Doctor en Filosofía de la Universidad de Salamanca, España. Docente de la Escuela de Comunicación Social y Periodismo de la Universidad Sergio Arboleda, Bogotá, Colombia. Pertenece al grupo de investigación CODICE de la Universidad Sergio Arboleda.

Correo electrónico: dune.valle@usa.edu.co

Valle, D. (2020). Humanismo y transhumanismo en el final de la metafísica: la era digital como paradigma de la metafísica de la subjetividad. Cuestiones de Filosofía, 6 (26), 75-97. doi: https://doi.org/10.19053/01235095.v6.n26.2020.11242 


\title{
Resumen
}

En el presente trabajo nos proponemos analizar el problema del humanismo y la técnica en la filosofía de Martin Heidegger, destacando su posición crítica frente a la idea de humanismo surgido en el marco de la tradición metafísica, pues sería la manifestación más visible de la subjetividad moderna. Esto se plasmaría, según Heidegger, en la filosofía de Nietzsche, especialmente en su interpretación de la voluntad de poder y en la figura del superhombre como consumación y fase última de la metafísica, donde la voluntad de dominar y disponer del hombre y de la naturaleza en todas sus formas expresa la destinación del ser como Gestell (lo dispuesto), que en la era digital se manifiesta en fenómenos tales como el dataísmo y el transhumanismo, cumpliendo así la interpretación que Heidegger adelantaba hace más de cincuenta años: la racionalidad técnico científica, a través del pensar calculante, se manifiesta como consumación de la metafísica

Palabras claves: humanismo, transhumanismo, técnica, metafísica, Nietzsche, Heidegger.

\begin{abstract}
This paper delves into Heidegger's views on humanism and technique. We emphasize his critics to the idea of humanism proposed by the traditional metaphysics that he considers the most prominent expression of Modernity's subject. Heidegger remarks how this idea can be found in Nietzsche's philosophy, mainly in his interpretation of the Power of Will and the Übermensch as the fulfillment, and last stage, of Metaphysics. In this metaphysical Gestell (stage), the human desire to dispose and dominate nature in all its forms expresses the destination of the Being. In the Digital Age, this desire manifests itself in movements like the dataism and Transhumanism, fulfilling the interpretation advanced by the Heidegger more than fifty years ago. The technical-scientific rationality becomes then the enforcement of Metaphysics towards its End.
\end{abstract}

Keywords: Humanism, transhumanism, technique, metaphysics, Nietzsche, Heidegger. 


\section{Introducción}

Sin lugar a dudas la humanidad parece deslumbrada por los desarrollos y beneficios que brindan las tecnologías de la información y la comunicación, propias de la era digital, en la cual las promesas del progreso ilimitado y la felicidad están a la orden del día. En este contexto nos proponemos analizar ciertos visos de la llamada crisis del humanismo y su relación con el despliegue planetario de la técnica en el horizonte del pensamiento contemporáneo. Este objetivo será llevado a cabo a través de la crítica heideggeriana a la metafísica tradicional, y en este caso en la figura del humanismo entendida como una expresión de la subjetividad moderna. Esto se manifestaría, según Heidegger, en la formulación de la voluntad de poder nietzscheana, en la que la voluntad de dominar y disponer del hombre y de la naturaleza a su antojo se expresaría en la era digital en el dataísmo y en el surgimiento de la figura de un superhombre bajo la égida del transhumanismo más radical.

\section{Humanismo y metafísica}

Seguramente a más de uno debe llamar la atención la notoriedad y relevancia que ha adquirido el concepto del humanismo en los últimos tiempos, pues parece ser que se ha transformado en la palabra clave de la cultura contemporánea, que engloba toda suerte de encomiables virtudes y sólidas creencias de la cultura occidental, refrendando así perdidas actitudes y prácticas de la antigüedad clásica y romana que reflejaban toda la riqueza intelectual, artística y cultural de la humanidad recuperada en el Renacimiento. Es por esta razón que:

El humanismo contemporáneo queda marcado por la añoranza de algo perdido y por lo incierto de una esperanza sin contenido. Así receloso en admitir una humanitas -difícilmente conciliable con la existencia histórica-, el pensamiento humanista admira las realizaciones humanas en el arte, el derecho -e incluso en las posibilidades que ofrecen las nuevas tecnologías- como expresiones de la verdad sobre las cosas y sobre nosotros mismos; y advierte que esta verdad nos convoca y hermana como ningún interés práctico puede hacerlo (Flamarique, 2000, p. 774).

Difícilmente se podría poner en tela de juicio o hacer un cuestionamiento a este conjunto de valores y prácticas humanas que suponen el humanismo, pues parece ser que "el ideal humanista representa el último reducto que acoge y resguarda las pocas cosas, convicciones sin las que la libertad 
y racionalidad se transforman en palabras vacías o valores contradictorios" (Flamarique, 2000, p. 774). Sería pues el humanismo una especie de reservorio de la historia de la humanidad en la que se alojan gran parte de las obras, pensamientos y prácticas humanas relevantes por su valor cultural imperecedero; obras tanto materiales como inmateriales, razón por la cual el término humanismo se entiende incluso como equivalente o sinónimo de cultura.

Sin embargo, se hace sentir desde algunos sectores cierto resquemor con la palabra humanismo que se traduce, según Vattimo (1987), en una crisis. A pesar de esto, sin embargo, es clara la pervivencia de su valoración, pues: "no deja de suscitar perplejidad la extraña unanimidad con que, de un rincón a otro (...) se celebra al "Humanismo". Desde las más variopintas posiciones, y como si tras tantas postrimerías se ansiara volver a sólidos principios" (Duque, 2003, p. 9). Esto a simple vista podría ser un indicio de que algo está mal o algo no anda bien en la sociedad contemporánea, signada por los desarrollos tecnológicos y la crisis medio ambiental. Podemos ver que a lo largo de la historia la pregunta o preocupación por el humanismo y sus valores resurge cada cierto tiempo, cuando la humanidad parece estar en peligro. Es justamente en estos escenarios donde se revitaliza o resurge con más fuerza la pregunta por el humanismo.

En estas preocupaciones se motivaría la apelación que Beaufret dirige a Heidegger y da origen, precisamente, a la Carta sobre el humanismo, en la que el pensador francés se pregunta: ¿Cómo devolverle el sentido a la palabra "Humanismo"? Esto sería un indicio de la preocupación de Beaufret por la situación histórica que enfrentaba la humanidad en aquel momento, signada claramente por los horrores y secuelas de la Segunda Guerra Mundial. En este conflicto, el aparataje bélico militar adquiría su poder de destrucción, precisamente, gracias al desarrollo técnico científico, que desde tiempo atrás, principalmente al alero del Positivismo y la Ilustración, se venía presentado como la solución y el camino directo para el desarrollo y progreso ilimitado de la humanidad en su totalidad; conduciéndola así, sin más, hacia una plenitud nunca vista en su historia.

Ahora bien, en este contexto Heidegger formula su crítica al concepto de humanismo en su famoso escrito de 1946. Heidegger presenta allí un cuestionamiento a las distintas figuras del humanismo que se han ido dando a lo largo de la historia, pues ve en ellas un elemento común: la interpretación de la esencia del hombre como sujeto, como substancia. En efecto, si entendemos 
la esencia del hombre como sujeto, si lo situamos como el fundamento subyacente, como la substancia sobre la cual se constituye el mundo y nuestra relación con lo que nos rodea -incluida la naturaleza y el medio ambiente-, lo que, según el filósofo alemán, sería una manifestación concreta del olvido del ser, esto no sería más que una consecuencia de aquella interpretación del ser que ha dominado la historia del pensamiento occidental sin ningún contrapeso, y en la que la relación sujeto objeto se establece como el modo privilegiado de conocimiento y acceso a la realidad. A juicio del pensador alemán, estas consideraciones no han hecho más que devaluar la pregunta por el ser del hombre, pues, en definitiva, "las 'categorías' de la filosofía tradicional -'substancia', 'sujeto', 'realidad', etc.- son radicalmente ineptas para apresar y expresar el ser del hombre, puesto que están pensadas solo en función y a partir de los 'vorhanden'” (Carpio, 1977, p. 204).

Ahora bien, esta consideración dominante ha llevado la tradición a interpretar los entes del mundo y su propia existencia desde este sentido, en lo que va involucrado cierta idea del tiempo. Esta concepción llama la atención de Heidegger, quien comenta: "resulta llamativo el hecho de que los griegos interpretaran el ser a partir del tiempo: ousía significa presencia, presente. Porque el ser significa esto, se puede decir que el verdadero ser es aquello que jamás está ausente, es decir, lo que está siempre ahí: aei on" (Heidegger, 2009, p. 97). El filósofo alemán sostiene que en la filosofía griega prima una consideración del ser que concibe que el verdadero ente, el ente por excelencia, está constantemente ahí, es decir, está presente en grado máximo y es la presencia o substancia constante por antonomasia.

En este mismo sentido, la noción de humanismo estaría claramente determinada por la metafísica y, por ende, toda pregunta relacionada con dicha idea debe partir y tener en cuenta esa determinación. Pues: "todo humanismo se basa en una metafísica, excepto cuando se convierte él mismo en el fundamento de la metafísica (...) y, en concreto desde la perspectiva del modo en que se determina la esencia del hombre, lo particular y propio de toda metafísica se revela en el hecho de que es 'humanista'. En consecuencia, todo humanismo sigue siendo metafísica” (Heidegger, 2006, p. 24).

En definitiva, la crítica de Heidegger se dirige principalmente hacia la concepción del ser de la tradición metafísica, pues todas las consideraciones y clases de humanismo presuponen y dan por supuesta que la esencia del ser humano, reconocida universalmente, es la de animal racional. El hombre 
sería entendido como un animal más entre otros, con el status distinto proveniente de la razón, pero aun dentro de esos parámetros. En otras palabras, "la metafísica piensa al hombre a partir de la animalitas y no lo piensa en función de su humanitas" (Heidegger, 2006, p. 27). Esto significaría, entre otras cosas, que no se pregunta por la esencia del hombre, ni por su sentido originario, sino que se le concibe desde una perspectiva cuyo modelo ontológico es la naturaleza: lo Vorhandenheit. Relegando a un segundo plano la importancia o valor de la constitución esencialmente histórica de la existencia y su relación de privilegio con el ser mismo, como un ente que se define principalmente por su mortalidad, entendida como su posibilidad más propia (Heidegger, 1997b).

Como es bien sabido, Heidegger ha cuestionado desde sus primeros cursos de Friburgo las definiciones o interpretaciones provenientes de la tradición filosófica que pretenden dar cuenta del hombre En este sentido se expresa el filósofo alemán, cuando afirma en 1923 que:

(...) al llamar "hombre" al existente que se va a investigar se le pone de antemano dentro de una determinada concepción categorial, puesto que el examen se lleva a cabo siguiendo la pauta de la definición tradicional de "animal racional" (...) la perspectiva que se tiene del hombre según la pauta de la definición de "animal rationale" hace que se le vea dentro del ámbito de los entes que junto con él existen en el modo de lo viviente (plantas, animales) (Heidegger, 1999, pp. 46-47).

Si bien critica estas definiciones, poniendo en cuestión su proveniencia, su origen, eso no significa que venga a decir que las interpretaciones humanísticas son falsas o carentes de legitimidad, pues lo que sostiene al respecto es que éstas son derivadas y no tienen un carácter originario: "Por el contrario, se puede afirmar que el único pensamiento es el de las supremas determinaciones humanísticas de la esencia del hombre que todavía no llegan a experimentar la auténtica dignidad del hombre" (Heidegger, 2006, p. 37). Esto implicaría que la pregunta por la esencia del hombre no solo quedaría completamente oscurecida, sino que, incluso, ni siquiera llega a ser planteada originariamente.

Heidegger plantea así una crítica al humanismo debido a que la humanitas del hombre no se ha posicionado en el lugar y altura que le corresponde, es decir, no se ha pensado de forma originaria. Ahora bien: "es claro que la altura esencial del hombre no consiste en que él sea substancia de lo ente en 
cuanto su 'sujeto' para luego, y puesto que él es el que tiene en sus manos el poder del ser, dejar que desaparezca el ser de lo ente en esa tan excesivamente celebrada 'objetividad"' (Heidegger, 2006, p. 38). Como podemos ver aquí, el filósofo de la Selva Negra presenta con claridad aquello a lo que se dirige cuando crítica al humanismo, y esto no tiene que ver con una idea contraria a los valores, ideales o máximas que han guiado los intereses del humanismo (del todo loables, sea dicho), sino, más bien, que está poniendo en tela de juicio es la concepción de la humanidad del hombre definida exclusivamente en estos términos.

Como Heidegger sostiene, el hombre es porque ha sido arrojado, ex-siste contra el arrojo del ser y, desde esa perspectiva, es más que un simple animal racional, pues es menos respecto al hombre que se entiende a partir de la subjetividad. El hombre no es amo y dominador de lo ente, sino que es "el pastor del ser" (Heidegger, 2006, p. 57). El humanismo así caracterizado, "piensa la humanidad del hombre desde su proximidad al ser (...) es un humanismo en el que lo que está en juego ya no es el hombre, sino la esencia histórica del hombre en su origen procedente de la verdad del ser" (Heidegger, 2006, p. 58). Ahora bien, si se considera la opción de conservar el concepto de humanismo, este adquiere una connotación peculiar, por decir lo menos, pues ahora la esencia del hombre es fundamental en su relación con la verdad del ser. El hombre debe ser interpretado a partir de su relación de ser con el ser mismo, como abierto a sus posibilidades y a su mortalidad como lo más propio (Heidegger, 1997b).

\section{Nietzsche y el estadio último de la metafísica de la subjetividad}

Como recordaremos, la crítica de Heidegger a la noción de humanismo se centraba, principalmente, en la idea de sujeto que predomina en las distintas interpretaciones que han tratado de dar cuenta del hombre a lo largo de la historia, pues se entiende al sujeto como fundamento y medida de lo existente. Una consecuencia directa es la interpretación técnica de nuestra época, que viene determinada desde la modernidad. Es decir, la esencia de la técnica moderna es idéntica a la esencia de la metafísica de la subjetividad, pues:

(...) en la metafísica se lleva a cabo la meditación sobre la esencia de lo ente así como una decisión sobre la esencia de la verdad. La metafísica fundamenta una era, desde el momento en que, por medio de una determinada interpretación de lo ente y una determinada concepción de la verdad, le procura a esta el fundamento de la forma de su esencia. Ese fundamento domina por 
completo todos los fenómenos que caracterizan dicha era, y viceversa: quien sepa meditar puede reconocer en estos fenómenos el fundamento metafísico (Heidegger, 2010, p. 63).

Y, en este caso, la técnica es metafísica, dado que ésta se caracteriza por mostrar al ente de una u otra forma de acuerdo con la concepción metafísica dominante, que en nuestra época se muestra como despliegue técnico científico o Gestell, y determina en modo decisivo la imagen del mundo y del hombre, estableciendo de antemano de qué forma se muestran los entes del mundo y cómo los comprendemos.

Ahora bien, en este contexto de la crítica heideggeriana a la metafísica de la subjetividad, surge la figura de Nietzsche, quien sería el que llevaría la metafísica a su "finalización", pues, como apunta Heidegger: "Debemos comprender la filosofía de Nietzsche como metafísica de la subjetividad (...) La metafísica de Nietzsche y por lo tanto el fundamento esencial del nihilismo clásico se pueden definir ahora con mayor precisión como metafísica de la incondicionada subjetividad de la voluntad de poder" (Heidegger, 2001, pp. 163-164). Es importante hacer notar que la interpretación heideggeriana de la filosofía de Nietzsche es en clave metafísica y no intenta dar cuenta de su pensamiento o sus ideas de forma cabal y apegada al texto, más bien apunta a leer su filosofía desde la historia del ser, desde la cual adquieren sentido todos los fenómenos de la era actual. Lo que hace el filósofo de la Selva Negra es utilizar la filosofía de Nietzsche para hablar de la situación del mundo contemporáneo. Valga esta aclaración, pues al "adoptar como hilo conductor y condición previa para la comprensión del sentido de los fenómenos la 'historia del ser', no es conjugable con la tarea de dar una interpretación 'correcta' del pensamiento de Nietzsche" (Sánchez, 2006, p. 341).

Ahora bien, si atendemos a la historia del ser en esta era como final de la metafísica:

En el pensamiento de Nietzsche (...) viene a la luz el ente como voluntad de poder, representando este pensamiento de la voluntad de poder el punto de llegada y la culminación de la prepotencia del ente sobre el ser. El olvido del ser es ahora completo en cuanto todo, incluso la verdad queda reducida al ente como voluntad de poder (...) El superhombre designa aquella humanidad que es exigida por esa totalidad (Sánchez, 2006, p. 351).

En la lectura que hace Heidegger resalta, entre otras cosas, la voluntad de poder y el superhombre como conceptos que permitirían mostrar de qué manera 
en el pensamiento de Nietzsche se manifiesta el cumplimiento definitivo de la metafísica de la subjetividad, y cómo estos conceptos revelarían esa posición metafísica propia de la era técnica con su afán de dominio absoluto sobre el ente humano y la naturaleza, donde el mundo se transforma en un objeto más de su dominio y voluntad. Esto exigiría para sí un nuevo hombre.

Heidegger sostiene al respecto:

El hombre cuya esencia es querida por la voluntad de poder, es el transhombre (Übermensch) (...) Nietzsche ha pensado la esencia de la humanidad que, en el destino del ser de la voluntad de poder ha sido determinada a asumir el dominio de la tierra (...) un ser que aparece en su esencia volitiva en cuanto voluntad de poder, y por medio de esa aparición hace época, concretamente la última época de la metafísica (Heidegger, 2010, pp. 187-188).

Esto significaría que el hombre a través de la voluntad de poder, expresada en la figura del superhombre, se transformaría en la medida absoluta y el centro de todas las cosas, lo que le permitiría disponer a su antojo de todo cuanto le hace frente. La tierra se revela solamente como un objeto a disposición para la manipulación y explotación del hombre. Así la naturaleza y el hombre solo se convierten en un objeto más de explotación para la técnica, que termina de esta manera ampliando su dominio sobre todo ente sin ningún contrapeso: "con el inicio de la lucha por el dominio de la tierra, la era de la subjetividad se encamina hacia su consumación” (Heidegger, 2010, p. 191).

Ahora bien, desde la óptica de Heidegger queda claro desde un principio que entre técnica y metafísica existe una conexión indisoluble. Esto significa que el despliegue planetario de la técnica moderna tiene un fundamento metafísico y tiene su origen en el pensamiento moderno como modulación de la historia del ser, que en definitiva es la interpretación de la esencia de la técnica como final de la metafísica. Final no quiere decir acabamiento ni cesación; significa ante todo que:

En la época moderna acaba la metafísica porque ella es su plenificación. Final no puede significar entonces mera cesación, ni tampoco interrupción, abandono o arrojamiento al "trastero de la historia", etc. Final quiere decir consumación, cumplimiento pleno, llevar hasta el extremo las posibilidades internas de algo, agotar todo lo que puede dar de sí (Rodríguez, 2006, p. 150).

En otras palabras, la metafísica ha llegado a su fin en la época moderna, esto quiere decir que ha desplegado completamente sus posibilidades a través del despliegue técnico como manifestación visible de la metafísica de 
la subjetividad y su correspondiente interpretación del ente y del mundo. Se evidencia aquí un desprendimiento o devaluación del ser hacia la maquinación (Machenshaft) en la era del acabamiento de la metafísica, donde "la lucha por el dominio de la tierra y el completo despliegue de la metafísica que lo sustenta lleva a su acabamiento una era de la tierra y de la humanidad histórica, aquí se realizan, en efecto, posibilidades extremas de la dominación del mundo y del intento que emprende el hombre por decidir sobre su esencia puramente desde sí" (Heidegger, 2001, p. 212). Lo que precisamente adquiere su relieve y manifestación más visible en el dominio absoluto del pensar técnico-científico. El final de la metafísica es, entonces, el instante histórico en el que se agotan las posibilidades esenciales de la metafísica, como consumación y despliegue en la época moderna de la interpretación griega del ser como presencia, que en la época actual se destina como técnica y subjetividad.

\section{Heidegger y el peligro de la técnica}

Heidegger percibió, especialmente en el llamado segundo periodo de su pensamiento, que el despliegue tecnológico correspondía a un fenómeno global con alcance planetario, que dirigiría y determinaría por largo tiempo el destino de la humanidad. Concibió también que las consecuencias y desarrollos de ésta alcanzarían todos los rincones de la realidad, es decir, influirían en el destino del hombre en su totalidad; la tierra y el hombre quedarían a merced de una interpretación unilateral de la realidad, signada de principio a fin por el pensar calculante.

En la conferencia Gelassenheit, que el filósofo de la Selva Negra presentó en 1955, sostiene que el hombre se encuentra en una peligrosa situación en la tierra. Sin embargo, dicho peligro no se fundamentaría en el temor a una Tercera Guerra Mundial, a la explosión de una nueva bomba atómica o a la destrucción medio ambiental, cuestiones de por sí bastante preocupantes, sino que, afirma Heidegger: "El hombre se encuentra en una situación peligrosa en esta tierra (...) en cuanto que la revolución de la técnica que se avecina en la era atómica pudiera fascinar al hombre, hechizarlo, deslumbrarlo y cegarlo de tal modo, que un día el pensar calculador pudiera llegar a ser el único válido y practicado" (Heidegger, 2002, p. 30). Como podemos ver, Heidegger vincula directamente el predominio y la revolución de la técnica con el dominio absoluto de una forma de pensar: el pensar calculante; relación en la cual estribaría aquel peligro supremo que enfrentaría la humanidad venidera. De alguna manera queda establecido que entre el dominio del pensar calculante 
y la revolución de la técnica se produce una relación de dependencia mutua, lo que sería el fundamento no expresado de la era técnica.

Ahora bien, en esta conferencia Heidegger expresa con total claridad su interpretación de la técnica, con la cual no pretende demonizar la tecnología y sus desarrollos, pues, a su juicio, sería de una enorme ceguera negar sus beneficios. Desde su perspectiva, lo preocupante radicaría en que no estamos enfrentando meditativamente, o desde la destinación del ser, estas transformaciones radicales que enfrenta la humanidad, es decir, estamos dejando en manos del pensar calculante y del racionalismo técnico-científico, y a su desarrollo técnico desmesurado, todas las respuestas a las preguntas e inquietudes del mundo contemporáneo. Así pues, "semejante pensar sigue siendo cálculo aun cuando no opere con números ni ponga en movimiento máquinas de sumar ni calculadoras electrónicas. El pensamiento que cuenta, calcula; calcula posibilidades continuamente nuevas, con perspectivas cada vez más ricas y a la vez más económicas” (Heidegger, 2002, p. 19).

Heidegger viene a decir que esta forma de pensar es la que determina el desarrollo y la esencia de la técnica, pues lo que buscan en último término los desarrollos técnico-científicos es sacar la mayor rentabilidad y provecho de todo aquello que tienen a su alcance y de aquello de lo que se puede disponer a través del cálculo, en el que los criterios de eficacia, optimización y productividad adquieren un valor superlativo. En este contexto, la ciencia y la tecnología prometen esclarecer y brindar toda suerte de soluciones y respuestas a la más variopinta gama de problemáticas presentes en la tierra, como hace notar Heidegger en Serenidad. Como ejemplo de esto Heidegger recuerda la declaración de un conjunto de científicos galardonados con el Premio Nobel, que sostenían con total obsecuencia que la ciencia era el camino directo a la felicidad sin más.

Sin embargo, como dice Heidegger, esto no es algo casual, sino que:

(...) se debe a que, desde hace algunos siglos, tiene lugar una revolución en todas las representaciones cardinales (massgebende Vorstellungen). Al hombre se le traslada así a otra realidad. Esta revolución radical de nuestro modo de ver el mundo se lleva a cabo en la filosofía moderna. De ahí nace una posición totalmente nueva del hombre en el mundo y respecto al mundo. Ahora el mundo aparece como un objeto al que el pensamiento calculador dirige sus ataques y a los que ya nada debe poder resistir. La naturaleza se convierte así en una única estación gigantesca de gasolina, en fuente de energía para la técnica y la industria modernas (Heidegger, 2002, p. 23). 
En otras palabras, esta situación estaría marcada por el despliegue de la esencia de la técnica moderna que domina toda interpretación del ente en su totalidad, donde el hombre y la naturaleza quedan sometidos a este dominio interpretativo unilateral. La naturaleza, el medio ambiente, la vida humana y social en su conjunto, se rigen bajo los dictados del cálculo y la planificación en todas sus esferas, lo que se agudiza en la llamada era digital. La esencia de la técnica no es nada técnico y no tiene nada que ver con aquellos artilugios, útiles, instrumentos, herramientas tecnológicas. Así, pues, como apunta Heidegger "Los poderes que en todas partes y a todas horas retan, encadenan, arrastran y acosan al hombre bajo alguna forma de utillaje o instalación técnica, estos poderes hace ya tiempo que han desbordado la voluntad y capacidad de decisión humana porque no han sido hechos por el hombre" (Heidegger, 2002, p. 25).

Es necesario precisar que esta posición va a contramano de lo que generalmente se sostiene respecto a las tecnologías y sus instrumentos, dado que gran parte de los discursos sostienen que "la máquina es un producto más del homo faber, la producimos nosotros, los seres humanos, por lo que comparte nuestros límites, nuestro mundo y, como producto, está sometida a nuestros designios. En resumen, la máquina está muy lejos de ser algo ajeno o independiente de lo humano" (Ramos \& Fuentes, 2020, p. 88).

Antes bien, la técnica no es obra exclusiva del hombre, ya que su valor, poder e importancia no dependen del hombre ni de su venia, pues su esencia y su verdad va más allá de todo quehacer y planificación propiamente humana y solo responde a una destinación del ser mismo. Asimismo, la técnica moderna no surge o debe su aparición a que el mundo contemporáneo sea el tiempo de las máquinas o de la técnica, sino más bien porque esta es una época técnica, maquinal, por ser una destinación del ser y no al contrario.

Para entender con mayor claridad este designio de la era de la técnica, debemos retrotraernos unos años antes a su escrito La pregunta por la técnica de 1953, en la que Heidegger (1997a) plantea de forma sistematizada su pensamiento respecto al fenómeno técnico, que desde la verdad del ser viene destinado en tanto Gestell (lo dispuesto) al hombre contemporáneo. En este sentido, si comprendemos la destinación del ser como lo dispuesto, atendemos el llamado del ser en nuestro tiempo presente, como aquello que nos concierne de forma directa y esencial, como lo más propio en todo lugar y en cualquier dimensión de la utilización o manipulación de instrumentos; más 
allá de cualquier objeto técnico determinado, más que toda máquina o tecnología de la información que nos haga frente y nos provoque técnicamente.

Ahora bien, das Gestell es un vocablo acuñado por Heidegger, que se compone del prefijo Ge (aquello que reúne, coliga, congrega), y el verbo stellen, que significa poner, colocar. Este término se entiende, entonces, como aquello que reúne o coliga: "Dispuesto significa lo reunidor de aquel poner, que pone al hombre, esto es, lo provoca a desocultar lo real en el modo de establecer en cuanto lo constante. Dispuesto significa el modo de desocultar que impera en la esencia de la técnica moderna y que al mismo tiempo no es nada técnico" (Heidegger, 1997a, p. 130). Desde esta óptica, como habíamos adelantado, se descarta cualquier intento de concebir la esencia de la técnica como un medio para un fin, o como un simple hacer del hombre, lo que llevaría a descartar completamente su interpretación instrumental y antropológica, por lo demás bastante corriente. Heidegger (1997a) denomina a este desocultar que impera en la era de la técnica como desocultar provocante.

El desocultar provocante es el que impera en todo cuanto hay y existe. Esto tiene como consecuencia directa la transformación del medio ambiente y de la naturaleza, que concebidas bajo este prisma solamente se consideran como una fuente inagotable de recursos y reservas. En otras palabras, solo se concibe como un almacén de reservas del cual es posible extraer la mayor cantidad de energías explotables, acumulables y disponibles para su explotación planificada, calculada y programada; ahí dispuesta para manipular y disponer de ella a nuestro antojo, para un consumo planificado y calculado (Linares, 2008; Acevedo, 1999).

Bajo la misma lógica y ratio la humanidad del hombre, el hombre mismo es considerado un ámbito, o un objeto más de explotación planificada y calculada, y así deviene mano de obra, cerebro en obra, material humano (Acevedo, 1999), en último término como constante. De esta manera:

(...) la técnica moderna, como el desocultar estableciente, no es un simple hacer humano. Por eso debemos tomar, tal y como se muestra, el pro-vocar que dispone al hombre a tomar lo real como constante. Este pro-vocar reúne al hombre en el establecer. Esto reuniente concentra al hombre a establecer lo real como constante (Bestand) (Heidegger, 1997a, p. 128).

Efectivamente, todo ente, incluido el hombre, es entendido como constante, esto quiere decir que todo ente es considerado como una reserva o un fondo explotable, reemplazable, manipulable y calculable, como algo constante 
que está ahí como objeto de explotación y así ejerce su dominio como señor de la tierra, bajo la destinación del ser como lo dispuesto (Gestell).

Como habíamos visto anteriormente, Heidegger vislumbra el peligro que se cierne sobre la tierra por el dominio incondicionado de la técnica moderna. A esto podríamos agregar que lo preocupante o peligroso no es la técnica en sí misma, sino que lo es la interpretación unilateral y absoluta que se hace de ella según los dictados del pensar calculante. Queda así oculta su esencia como lo dispuesto, en un desocultar provocante que interpela al ente a aparecer como constante. A este respecto, aclara Heidegger:

La amenaza no le viene al hombre principalmente de que las máquinas y aparatos de la técnica puedan actuar quizás de modo mortífero. La más peculiar amenaza se ha introducido en la esencia del hombre. El dominio de lo dis-puesto amenaza con la posibilidad de que el hombre pueda rehusarse a retrotraerse a un desocultar más originario (Heidegger, 1997a, p. 139).

Cómo sostiene el pensador alemán, la amenaza no la constituyen los objetos técnicos ni tampoco sus aplicaciones: el peligro lo constituye el dominar absoluto de lo dispuesto como la única y excluyente modalidad de desvelamiento, de verdad. Heidegger hace una invitación a pensar meditativamente en este despliegue desmesurado de la tecnología y en sus consecuencias, buscando o ejercitando una forma de desocultar más originaria que corresponda a esa esencia de la técnica moderna no solo como lo dispuesto o constante. En otras palabras, en un desocultar que no devalúe la esencia del hombre y la naturaleza en simple objeto a su disposición, explotación y dominio incondicionado, sometido a los caprichos del señor de la tierra.

\section{Dataismo y transhumanismo: la consumación de la metafísica de la sub- jetividad en la era digital}

Hace más de cincuenta años Heidegger prestaba especial atención a las tecnologías de la información y comunicación que comenzaban a hacerse cada vez más omnipresentes en aquel entonces, cuando la ciencia cibernética daba sus primeros pasos con la obra de Norbert Wiener publicada en 1948. En este texto Wiener sentaba las bases y las definiciones de la llamada era digital y afirmaba que la tesis fundamental de su libro "consiste en que sólo puede entenderse la sociedad mediante el estudio de los mensajes y de las facilidades de comunicación de que ella dispone y, además, que, en el futuro, desempeñarán un papel cada vez más preponderante los mensajes cursados entre 
hombre y máquinas, entre máquinas y hombres y entre máquina y máquina" (Wiener, 1988, p. 16). Se daría inicio así a una nueva ciencia, a una nueva era de la historia de Occidente, marcada por las tecnologías de la información y la comunicación, en la que éstas tomarían el protagonismo absoluto para señalar el progreso y el desarrollo social en todas sus esferas, a tal nivel que se ha llegado incluso a denominar la era actual como Sociedad de la Información.

Ahora bien, este hito no fue ignorado por Heidegger, quien le prestó especial atención, dejando en claro su preocupación respecto a estas propuestas, tal como lo sostenía en 1966 cuando pronunciaba la conferencia El final de la filosofía y la tarea del pensar. En esta conferencia Heidegger expresa con total claridad su preocupación por el poder que está adquiriendo dicha ciencia, e incluso llega a situarla a un nivel equivalente a la técnica, es decir, como la manifestación más visible de la razón técnico científica. En este sentido afirma:

(...) no hace falta ser profeta para saber que las ciencias que se van estableciendo, estarán dentro de poco determinadas y dirigidas por la nueva ciencia fundamental, que se llama Cibernética. Esta corresponde al destino del hombre como ser activo y social, pues es la teoría para dirigir la posible planificación y el trabajo y organización del trabajo humano. La cibernética transforma el lenguaje en intercambio de información. Las artes se transforman en instrumentos de información manipulados y manipuladores (Heidegger, 2000, p. 79).

Como podemos ver, el filósofo alemán preludiaba de alguna forma la situación que enfrenta el hombre contemporáneo con la revolución tecnológica, y preveía una simplificación de la realidad y del hombre bajo el dominio de esta nueva ciencia, que, como hemos dicho, sería la ciencia de la racionalidad técnico científica por antonomasia y su adalid más destacado: el pensar calculante. Esto, en definitiva, sería el fiel reflejo del final de la metafísica y, por ende, de la filosofía, que se devaluaría, según Heidegger, en pura cientificidad cuyo rasgo fundamental sería la cibernética y su carácter técnico.

\section{Dataísmo y pensar calculante}

Ciertamente, nadie podría negar en la actualidad la prevalencia o el dominio absoluto que ha adquirido la cibernética en todos los ámbitos de la sociedad, pues las tecnologías de la información y la comunicación se han transformado en elementos de uso imprescindible para llevar a cabo cualquier trabajo 
o actividad que demande la vida cotidiana en casi en todas las esferas de la vida personal y social. Esto daría nacimiento a una nueva era: la era digital. En este escenario la utilización de internet, Big Data, redes sociales, teléfonos inteligentes y una serie de aplicaciones de diversa índole, diseñadas por los genios de Sillicon Valley, se convierte en un imperativo y una obligación quasi ontológica en esta nueva definición o comprensión del ser humano, cuyas relaciones sociales, comunicativas, así como su libertad, adquieren un nuevo estatus: estar conectado las veinticuatro horas del día.

El hombre de la era digital está determinado en su constitución desde el cálculo y la planificación a la que está sometido continua y libremente en cada momento de su vida online, en la que todas las interacciones o acciones que ejercemos cuando utilizamos estas tecnologías se convierten en datos que quedan almacenados en el Big Data, con el objetivo de hacer el mejor uso de ellos. Esto traduce en monetizar toda aquella información obtenida por nuestra navegación en la web. Las consecuencias más visibles de dicha monetización serían la personalización de la información que recibimos, las recomendaciones de productos, amigos, películas, rutas, viajes, noticias, parejas etc., que son enviadas por las empresas que han invertido en la consecución de esos datos. Todo esto con la promesa de que el único objetivo que se persigue con estas acciones es facilitarnos la vida.

Se ha de puntualizar que en estas promesas y utopías subyace una ideología de un determinado carácter filosófico que la sostiene. Nos encontraríamos, según esto, subsumidos en una ideología técnica (Garcia \& Valle, 2020), que en una de sus vertientes más representativa puede ser denominada dataísmo. Una definición que propone van Dijk al respecto es la siguiente:

El dataísmo revela una creencia en la objetividad de la cuantificación y en el potencial de rastrear todo tipo de comportamiento y socialidad humana a través de datos en línea. En segundo lugar, los (meta) datos se presentan como "materia prima" que puede analizarse y procesarse en algoritmos predictivos sobre el comportamiento humano futuro, activos valiosos en la industria minera. Los métodos cuantitativos piden interrogatorios cualitativos para refutar la afirmación de que los patrones de datos son fenómenos "naturales" (van Dijk, 2014, p. 201).

En esta creencia se sostienen gran parte de las promesas y utopías presentes en la era digital, que consideran que gran parte de los problemas humanos y sociales se podrán comprender y solucionar gracias a la gran cantidad de 
datos que recogen los monopolios tecnológicos de la navegación web de todos los usuarios de internet, en el que toda información se convierte en dato $y$, en consecuencia, puede ser cuantificada, mensurada y así monetizada. En definitiva, "el hombre digital digita en el sentido que cuenta y calcula constantemente. Lo digital absolutiza el número y el contar (...) Hoy todo se hace numerable, para transformarlo en el lenguaje de rendimiento, de la eficiencia. Así hoy deja de ser todo lo que no puede contarse numéricamente" (Han, 2014b, p. 42).

No obstante, el discurso de esta doctrina nos hace creer que el manejo de estos datos solo tiene valor social, benéfico y neutral, esto es, que dicho manejo no responde a ningún tipo de interés político o comercial. En este sentido: "la popularización de la datificación como un paradigma neutral, llevado por una creencia en el dataísmo y apoyada por guardianes de confianza institucionales, gradualmente arrojó una visión de la vigilancia de datos como una forma 'normal' de monitoreo social"' (van Dijk, 2014, p. 206).

En un contexto de cuantificación y medición cuantitativa de la realidad, a través de las conductas que los usuarios tienen en su vida online, se sostiene un nuevo paradigma propio de la revolución técnico científica, en la que impera absolutamente el pensar calculante y sus supuestos. De esta manera, cada click, gusto, búsqueda, interacción, relación comunicativa, sentimiento que expresamos a través del uso de estas tecnologías de la información y la comunicación, se pueden transformar en datos para su posterior utilización y, por qué no decirlo, manipulación de las conductas humanas. Todo esto se consigue por medio del perfilamiento psicológico que logran las redes con nuestros datos, lo que nos conduciría, según Han, a un totalitarismo digital (Han, 2014a, p. 47), esto es, a una barbarie de los datos, donde el imperativo del cálculo y la medida domina todas las esferas de la sociedad para lograr aumentar la optimización, productividad y rendimiento del hombre contemporáneo. De esta forma se pondría en peligro la soberanía, autodeterminación y libre albedrío del hombre signado por lo digital. Como sostiene Han, "la persona misma se positiviza en cosa que es cuantificable, mensurable, controlable. Sin embargo, ninguna cosa es libre. Sin duda alguna, la cosa es más transparente que la persona. El Big data es el fin de la persona y de la voluntad libre" (Han, 2014a, p. 14).

En definitiva, el dataísmo reclama para sí la redención de toda problemática o dificultad bajo el imperio de la tecnología y los datos, como receta perfecta 
para el desarrollo y progreso de la humanidad. Transforma, en consecuencia, al propio hombre, que ya no es considerado como simple objeto, trabajador o producto de consumo, ni siquiera ya una cosa, sino que se reduce a un dato cuantificable y mensurable. Es decir, tal como afirmaba Heidegger, en constante (Bestand), como insumo o capital humano ahí dispuesto para su explotación comercial, gracias a la prevalencia sin contrapeso del cálculo y la planificación en todas las esferas de nuestra existencia por medio de las tecnologías.

\section{El superhombre nietzscheano en la utopía transhumanista}

La mayor parte del planeta ve cada día con menos asombro la cantidad ingente de avances tecnológicos que se presentan de forma constante, casi cotidiana. Desarrollos que por lo general se fundamentan en los éxitos de la inteligencia artificial y su capacidad para apoyar los distintos procesos humanos y sociales en la salud, la economía, el derecho, la planificación social, etc. A pesar de los beneficios que nos han brindado este tipo de avances tecnológicos, con la inteligencia artificial a la cabeza, no podemos soslayar algunas de las preocupaciones que éstos han despertado en parte de la sociedad. Preocupaciones que se dirigen principalmente hacia las consecuencias humanas resultantes de la aplicación de estos avances, cuyos efectos en nuestra vida cotidiana están apenas visibles para gran parte de los usuarios de dichas tecnologías.

Sin embargo, lo que es aún más inquietante son las utopías que emergen desde una razón técnico-científica que no parece tener más límites que su propia imaginación, prometiendo así una infinidad de beneficios, desarrollos y avances de toda índole para la humanidad; promesas que muchas veces, como sostienen algunos pensadores, no poseen una base científica sólida (Sadin, 2014; Diéguez, 2017). Todo esto ha derivado en un nuevo ismo: el transhumanismo.

Este movimiento o filosofía, si se quiere, plantea en una de sus corrientes más radicales que:

La muerte empieza a no ser vista como un destino, como una condición básica e inexorable de nuestro ser en el mundo, de nuestra índole biológica, o como un referente de nuestra comprensión como seres humanos, tal como las religiones y la filosofía nos habían venido enseñando, sino que se está transformando en un problema técnico. Algo que tarde o temprano nuestro ingenio podrá solventar (Diéguez, 2017, p. 7). 
Nos situaríamos, de esta manera, en el estadio último del progreso de la tecnología, que con sus desarrollos permite al fin crear ese superhombre que dejará de temer a la muerte y se encumbrará como amo y señor de la tierra, capaz a fin de disponer, no solo de la tierra, sino también de la muerte y hacerla desaparecer. Se terminaría de esta manera con toda debilidad humana y con la finitud de la existencia, alejando, de paso, al hombre del dolor y el sufrimiento gracias al desarrollo tecnológico (Valle, 2018). Finalmente, gracias al desarrollo tecnológico, el hombre lograría su ansiada inmortalidad y se alejaría del dolor y el sufrimiento. Es importante hacer notar que este movimiento está dirigido principalmente por los responsables de los monopolios tecnológicos de internet que manejan y administran los datos de los usuarios: “todos ellos están convencidos de que las tecnologías (...) van a transformar todo para 'mejorar' hasta la vida misma, que finalmente quedará liberada de su término" (Sadin, 2018, p. 220).

Es necesario hacer algunas precisiones respecto al concepto de transhumanismo, pues, como es de suponer, tiene las más variadas interpretaciones, más allá de aquellas corrientes que propugnan una suerte de perfeccionamiento del potencial del ser humano en todas sus esferas, haciendo del progreso humano su meta principal. Comprendiendo al ser humano como un ente que puede ser mejorado y no solo en su dimensión física, sino también psicológica, cognitiva y moral, donde la tecnología sería la que permitiría todo tipo de mejoras. Esta visión, apunta Diéguez (2017), no sería nada novedosa, pues dicha perspectiva habría sido refrendada por distintos pensadores que han dejado manifiestas las limitaciones del ser humano, mostrando que su perfeccionamiento no era solo deseable sino necesario. En este contexto destacan las figuras de Bacon, Rousseau, Hegel, Schopenhauer, Nietzsche, Lessing, Unamuno, Ortega y Gasset.

Por otra parte, como comenta Luc Ferry, el transhumanismo

(...) es el heredero, un tanto, paradójico, pero verosímil en muchos aspectos, de una cierta forma de humanismo clásico, el que insiste (...) sobre la perfectibilidad infinita de este ser humano que no está en un principio encerrado en una naturaleza intangible y determinante, como puede serlo un animal guiado por la programación instinto natural común a su especie. El transhumanismo también puede ser heredero del optimismo cientificista y tecnófilo que se ha desarrollado en la Edad Moderna a partir de la Ilustración y de la revolución científica hasta el nacimiento de los NBIC, la robótica y la inteligencia artificial (Luc Ferry, 2017, p. 40).

Valle, D. (2020). Humanismo y transhumanismo en el final de la metafísica: la era digital 
Sin embargo, algo bastante distinto sería la corriente transhumanista representada principalmente por Ray Kurzweil, que se traduciría, a juicio de Luc Ferry, en un preocupante proyecto cibernético que propone:

Una hibridación sistemática de hombre/máquina que recurre a la robótica y a la inteligencia artificial más que a la biología (...) se trata de crear una especie nueva, radicalmente diferente de la nuestra, miles de veces más inteligente y poderosa que ella, una humanidad diferente, para la que la memoria, las emociones, la inteligencia, todo lo que se relaciona con la vida del espíritu, se podría almacenar en soportes materiales de un tipo nuevo. Como cargamos ficheros en una USB (...) Podríamos entonces: 1) separar la inteligencia y las emociones del cuerpo biológico (como la información y su soporte) y 2) almacenar la memoria, así como la conciencia, en máquinas (...) que no dejan de recibir un eco mayoritario en el mundo de los especialistas de la inteligencia artificial (Luc Ferry, 2017, p. 42).

Esta propuesta apuntaría a conseguir la ansiada inmortalidad, dejando atrás las limitaciones de nuestro cuerpo finito e imperfecto. Esto podrá ser logrado a través de la superación de dichas limitaciones en manos de la tecnología, según la cual la dualidad cuerpo y alma queda subsumida en la de máquina y datos. Esta dualidad es concebida como el nuevo reservorio de la humanidad del hombre. La vida del espíritu y el ser del hombre quedan reducidos por tanto "a un sistema de tratamiento de información que equipara el cerebro con una estricta calculadora" (Sadin, 2018, p. 227). No es asunto menor que esta propuesta tenga amplio apoyo en los especialistas en inteligencia artificial, pues ellos parecen ser los llamados a dirigir el destino del hombre. En sus manos está conducir el progreso sin límites de la humanidad, según afirman los transhumanistas.

El destino técnico del hombre como Gestell parece consumarse al mismo tiempo con la metafísica de la subjetividad en sus manifestaciones más notorias en la era digital, lo que plantea una "incertidumbre acerca de la esencia del hombre, justamente porque los seres humanos se han convertido en el fondo de reserva (...) materia prima del mundo tecnológico" (Linares, 2008, p. 106). La existencia se convertiría en la substancia por antonomasia, la presencia eterna del ser humano, a través de la inteligencia artificial y la pervivencia inmortal de la existencia y sus procesos cerebrales, emociones y sentimientos en un dispositivo cibernético, donde sería posible almacenar el ser del hombre en un nuevo híbrido superhumano. Resuena en esta interpretación la tesis metafísica del ser como presencia: una presencia eterna que 
pervive en el compuesto máquina y datos, como la humanidad peculiar al superhombre, reclamado por la voluntad incondicionada de dominio sobre el hombre y la tierra. Se presenta así la disolución absoluta de la diferencia entre el ser y el ente llamado hombre, llegando incluso a identificarse completamente.

Ahora bien, como dice Duque (2002), cualquier conocedor de Nietzsche podría poner en entredicho la comparación o relación entre estos tecno-organismo y cuerpos superhumanos con el planteamiento del superhombre, prevención surgida con toda razón. Sin embargo, lo que está fuera de discusión es lo mencionado por Heidegger en su Carta sobre el humanismo. La crisis del humanismo que se manifestaría a "causa de un proceso general de deshumanización que comprende ora el eclipse de los ideales humanistas de la cultura en favor de una formación del hombre centrada en la ciencia y en la facultades productivas racionalmente dirigidas" (Vattimo, 1987, p. 35), que como hemos visto tienen como fiel reflejo las utopías y supuestos de la era digital.

\section{Conclusiones}

Ciertamente a través de los desarrollos y promesas surgidas en la era digital, cuyo epítome serían el dataísmo y el transhumanismo, se cumplirían plenamente las preocupaciones que Heidegger manifestaba en su interpretación de la era técnica. Época donde la metafísica de la subjetividad llega a su cumplimiento y lleva al extremo sus posibilidades en el presente. Así, la voluntad de dominio incondicionado sobre todo ente se expresa, por una parte, en la vertiente más dura del transhumanismo, que promete el advenimiento de un superhombre de carácter inmortal en una hibridación hombre máquina, $\mathrm{y}$, por otra, el dataísmo, que a través del rastreo y acumulación de la mayor cantidad de datos, promete prever y solucionar, a través del cálculo, la planificación y medida de nuestras conductas, todas la problemáticas presentes y futuras de la existencia, lo que sin lugar a dudas nos llevaría directamente a una vida más plena y feliz, como el gran relato del siglo XXI.

¿Cómo devolver el sentido a la palabra humanismo? Difícil responder, quizá, como sostiene Heidegger, teniendo en cuenta el peligro que se cierne sobre el hombre contemporáneo, dominado y subyugado por las tenazas de las tecnologías y sus discursos. Pensando en las consecuencias humanas de estos desarrollos surgidos en la era digital, en la que la libertad y el ser más propio del hombre parece estar amenazado por los designios de la manipulación y el cálculo. 


\section{Referencias}

Acevedo, J. (1999). Heidegger y la época de la técnica. Santiago: Editorial Universitaria.

Carpio, A. (1977). El sentido de la historia de la filosofía. Buenos Aires: EUDEBA.

Diéguez, A. (2017). Transhumanismo. Barcelona: Herder.

Duque, F. (2003). Contra el humanismo. Madrid: Abada Editores.

Flamarique, L. (2000). El humanismo y el final de la filosofía. Anuario filosófico, 33 (68), pp. 773-796.

Ferry, L. (2017). La revolución transhumanista. Madrid: Alianza.

García \& Valle. (2020). Los impactos de la ideología técnica y la cultura algorítmica en la sociedad: una aproximación crítica. Revista de Estudios Sociales, 2020 (71), pp. 15-27.

Han, B. C. (2014a). Psicopolitica. Barcelona: Herder.

Han, B. C. (2014b). En el enjambre. Barcelona: Herder.

Heidegger, M. (1997a). Ser y tiempo. Santiago: Editorial Universitaria.

Heidegger, M. (1997b). Filosofía, ciencia y técnica. Santiago: Editorial Universitaria.

Heidegger, M. (1999). Ontología: hermenéutica de la facticidad. Madrid: Alianza.

Heidegger, M. (2000). Tiempo y ser. Madrid: Tecnos.

Heidegger, M. (2001). Nietzsche II. Barcelona: Destino.

Heidegger, M. (2002). Serenidad. Barcelona: Ediciones del Serbal.

Heidegger, M. (2006). Carta sobre el humanismo. Madrid: Alianza.

Heidegger, M. (2009). Tiempo e historia. Madrid: Trotta.

Heidegger, M. (2010). Caminos de bosque. Madrid: Alianza. 
Linares, J. (2008). Ética y mundo tecnológico. México: FCE.

Ramos \& Fuentes. (2020). Tecnología y Transparencia. Trans /form/acao: Revista de Filosofía, 43 (1), pp. 77-98.

Rodríguez, R. (2006). Heidegger y la crisis de la época moderna. Madrid: Síntesis.

Sadin, E. (2018). La siliconización del mundo. Buenos Aires: Caja Negra.

Sánchez, D. (2006). La experiencia dionisiaca del mundo. Madrid: Técnos.

van Dijck, J. (2014). Datafication, dataism and dataveillance: Big Data between scientific paradigm and ideology. Surveillance \& Society, 12 (2), pp. 197-208.

Valle, D. (2018). Dolor y autoexplotación en la era digital. Contrastes. Revista Internacional de Filosofía, 23 (3), pp. 163-180.

Vattimo, G. (1987). El fin de la modernidad. Barcelona: Gedisa.

Wiener, N. (1988). Cibernética y sociedad. Buenos Aires: Editorial Sudamericana. 